\title{
PREPARATION, MICROWAVE AND MAGNETIC FIELD RESPONSE OF YBaCuO THIN FILM MICROBRIDGES*
}

\author{
B. HÄUSER, B. B. G. KLOPMAN and H. ROGALLA \\ University of Twente, Department of Applied Physics, P.O.B. 217, 7500 AE Enschede \\ (The Netherlands)
}

(Received November 8, 1988)

\section{Summary}

On $\mathrm{YBaCuO}$ thin films, which were deposited at ambient temperature and were superconducting after post-deposition annealing in oxygen, microbridges and d.c. superconducting quantium interference devices (SQUIDs) were constructed by lift-off. Over a temperature range from 4.2 to $>70 \mathrm{~K}$ the devices show well-developed Josephson-like behaviour when irradiated with microwaves. Also, SQUID operation can be observed in this temperature range.

Thin superconducting films of $\mathrm{YBaCuO}$ were sputtered by r.f.-magnetron onto $\mathrm{MgO}$ substrates from a stoichiometric ceramic target [1]. During the deposition, the films were kept at ambient temperature. The films were then annealed at $920^{\circ} \mathrm{C}$ in flowing oxygen, after which they show electrical transitions to superconductivity with zero resistance at about $80 \mathrm{~K}$.

As a result of the low deposition temperatures, standard photoresist can be used for construction of the thin films by lift-off technique [2]. In that way, single microbridges as well as d.c. superconducting quantum interference devices (SQUIDs) and flux transformers were made. The width of the microbridges was below $10 \mu \mathrm{m}$, the thickness of the films typically being $400 \mathrm{~nm}$. The operating temperature of the resulting devices reveals that almost no degradation of the film properties takes place during this lithographic process.

For microbridge applications, low critical current densities $J_{c}$ are desirable. Typically, films with critical current densities of $2 \times 10^{5} \mathrm{~A} \mathrm{~cm}^{-2}$ at $4.2 \mathrm{~K}$ and $10^{3} \mathrm{~A} \mathrm{~cm}^{2}$ at $74 \mathrm{~K}$ were used for our measurements (Fig. 1), determined after construction of the devices and including the small degradation of the superconducting properties by the lithographic process.

*Paper presented at the Symposium on High Temperature Superconductors - Preparation and Applications, at the E-MRS Fall Meeting, Strasbourg, November 8 - 10, 1988. 
The microwave measurements were carried out using $x$-band $(9.34 \mathrm{GHz})$ microwave equipment with a klystron source [3]. The incident microwave power was measured with a $30 \mathrm{~dB}$ direction coupler and the $I-V$ characteristics were determined by a four-terminal method. The temperature in the helium cryostat can be varied between $4.2 \mathrm{~K}$ and room temperature.

On application of microwave power, well-developed microwave-induced steps in the $I-V$ characteristics are visible. Increasing the power results in re-entrant behaviour of the step current values $I_{c n}$ (Fig. 2), as is generally observed in Josephson junctions but not in wide microbridges. These measurements were carried out at different temperatures. The Bessel-functionlike behaviour was observed at all temperatures up to $71 \mathrm{~K}$, except at very low temperatures $(4.2 \mathrm{~K})$, as the available microwave power $\left(6 \times 10^{-2} \mathrm{~mW}\right)$ was not sufficient to suppress the $I_{\mathrm{c} 0}$ in this case.

On application of an external perpendicular magnetic field, d.c.-SQUID operation can be observed. For these measurements, d.c.-SQUIDs with a coupling hole of $4200 \mu \mathrm{m}^{2}$ and microbridges with a width of $40 \mu \mathrm{m}$ each were chosen because of the lower critical current densities in the case of the polycrystalline films $(2.5 \mathrm{kA}$ at $4.2 \mathrm{~K})$. Because of this polycrystalline structure of the films, the modulation behaviour is quite complicated at low $(T<40 \mathrm{~K})$ temperatures. In this case, a very high modulation voltage was achieved $\left(V_{\text {mod }}=20 \mu \mathrm{V}\right)$; the small modulation period indicates increase in SQUID sensitivity by enhanced flux compression. Nevertheless, the quite irregular modulation behaviour seems to stem from a network-like behaviour of the Josephson junctions in the microbridge region. At higher temperatures $(T>40 \mathrm{~K})$ a clear SQUID modulation can be seen with modulation voltages up to $8 \mu \mathrm{V}$. From these values a temperature-dependent effective area of the SQUID, a result of flux compression, of $6000 \mu \mathrm{m}^{2}$ at $39 \mathrm{~K}$ and $4500 \mu \mathrm{m}^{2}$ at $62 \mathrm{~K}$ can be deducted. Coupling of a single-coil superconducting flux transformer to the SQUID further extends the SQUID's field detection limit.

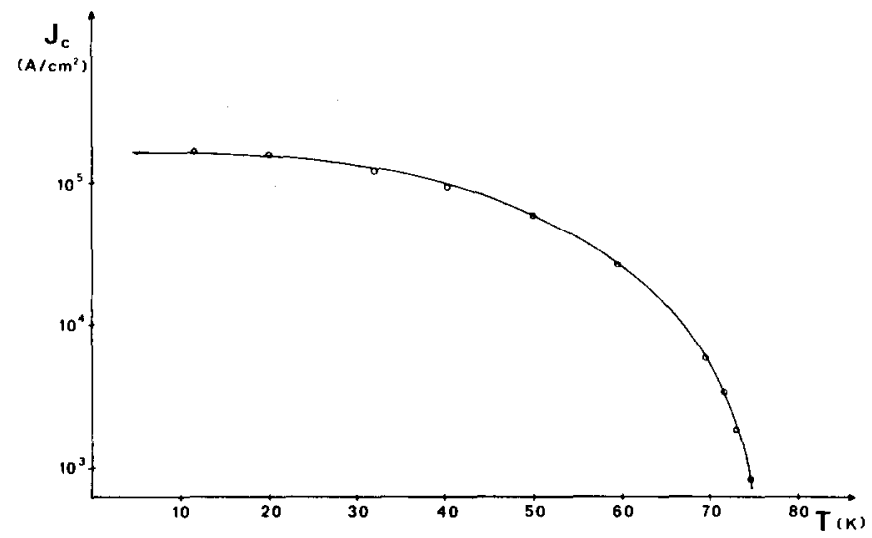

Fig. 1. Temperature dependence of the critical current density $J_{c}$ of the microwave-irradiated microbridge. 


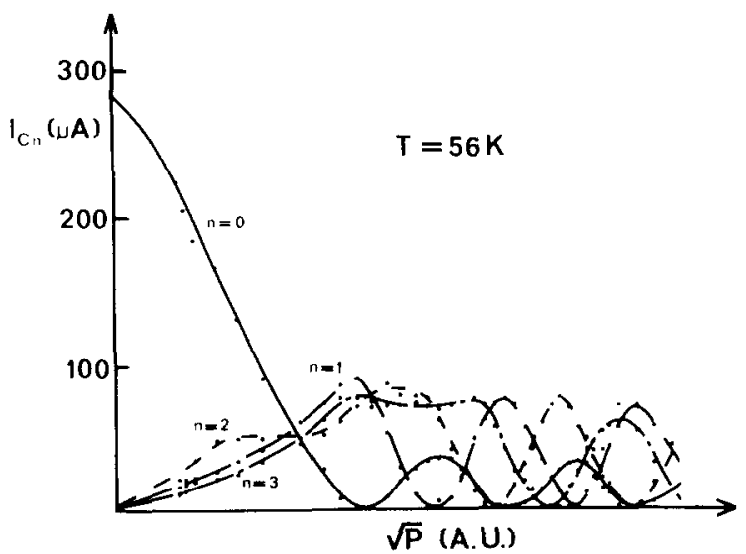

Fig. 2. Dependence of the critical current $I_{c 0}$ and the microwave-induced steps $I_{c n}(n=1,2,3)$ on the irradiated microwave power at $56 \mathrm{~K}$.

\section{References}

1 B. Häuser and H. Rogalla, in S. A. Wolf and V. Z. Kresin (eds.), Novel Superconductivity, Plenum Press, New York, 1987, p. 951.

2 B. Häuser and H. Rogalla, Appl. Phys. Lett., 52 (10) (1988) 844.

3 B. Häuser, B. B. G. Klopman, D. Blank and H. Rogalla, Proc. ASC, San Francisco, 1988, IEEE Trans. Mag., in the press. 